\title{
The Impact of Deep Foundations of Building Structures on the Neighbouring Buildings - a Static Analysis
}

\author{
Czesław Miedziałowski, Damian Siwik* \\ Institute of Civil Engineering, Bialystok Technical University, Białystok, Poland \\ *Corresponding author: d.siwik@o2.pl
}

Received July 18, 2014; Revised August 05, 2014; Accepted August 12, 2014

\begin{abstract}
Deep foundations of buildings and their impact on neighbouring buildings is one of the most important issues when planning a new facility. Whereas, the analyses of the threats often come down only to a simplified evaluation of the building subsidence and to comparing them with the limit values. The paper presents the methodologies for using the subsidence surface of the land behind the housing wall of the excavation to assess the impact of additional displacements on the technical condition of facilities, through the determination of the distribution and the values of stresses in the estimated structure.
\end{abstract}

\section{Keywords: deep foundation, adjacent buildings, Finite Element Method, FEM}

Cite This Article: Czesław Miedziałowski, and Damian Siwik, "The Impact of Deep Foundations of Building Structures on the Neighbouring Buildings - a Static Analysis." American Journal of Civil Engineering and Architecture, vol. 2, no. 4 (2014): 136-142. doi: 10.12691/ajcea-2-4-3.

\section{Introduction}

The analysis of the impact of deep foundation of the building (e.g. foundation in a deep excavation) on neighbouring facilities requires the engineer/designer to examine two basic static patterns:
- the phase of the excavation (Figure 1a) - due to the relaxation of the excavation floor the displacement of soil occurs, and thus of the objects in the vicinity,

- the phase of the operation of the building (Figure 1b) - the preloading of the soil with the building results in subsidence of the newly formed structure and of the facility in its vicinity.

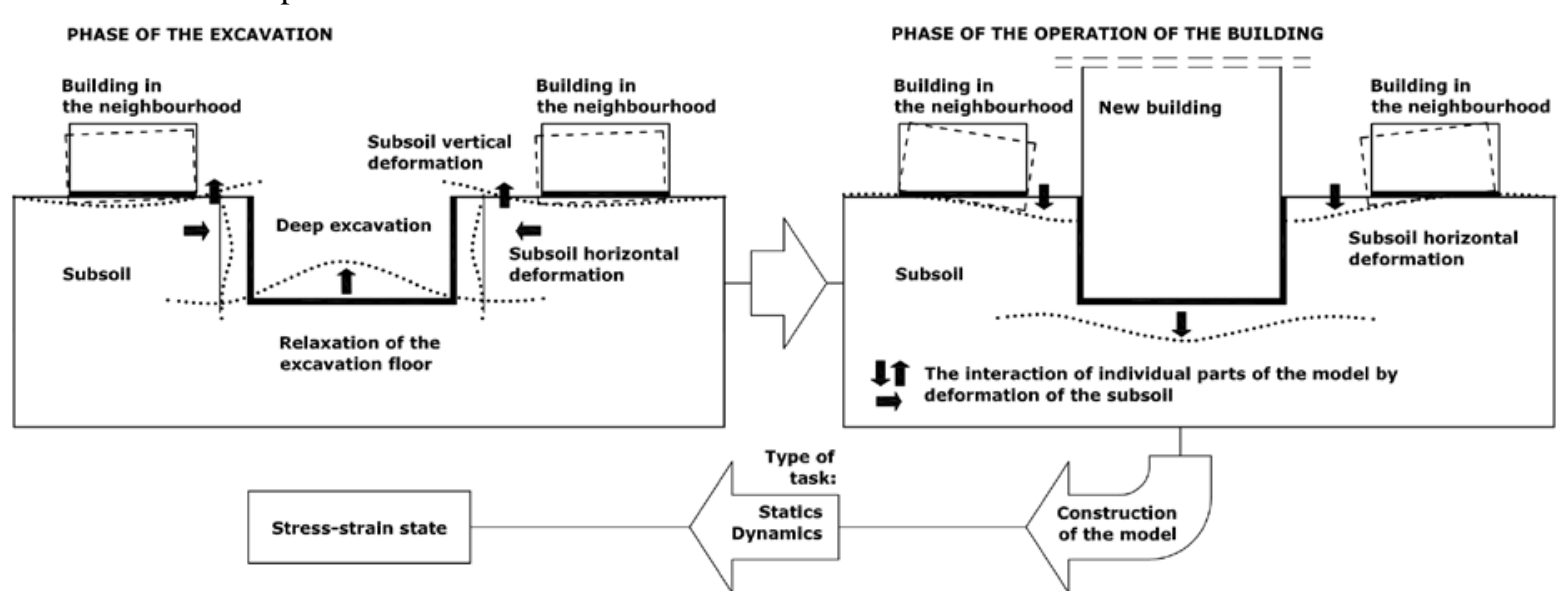

Figure 1. The implementation phases of the calculations in the analysis of the impact of a deep foundation of the building on the adjacent buildings: a) phase of the excavation; b) phase of the operation of the building

Whereas, the deformation of the land, in the operation phase of the building can occur both in the form of subsidence and uplifts due to an earlier relaxation of the excavation. The shape of the subsidence of displacements behind the housing wall depends, among others, on the depth of the excavation, the type of the casing used and its static diagram [12].

The basic tool for the analysis of this type of issues is currently the Finite Element Method (FEM) [24]. Whereas, if the use of the numerical method, in the case of simple two-dimensional systems does not cause many problems. Then, in the case of three-dimensional issues, especially in the case of interactive systems: a building-soilneighbouring buildings (Figure 2), there may appear difficulties with equipment, which does not allow for the analysis of such large computational tasks.

Due to the threat posed by a new implementation of the facility with deep foundation on the existing buildings, the issues of this type should be thoroughly analysed as early as at the design stage of construction $([6,9,17])$. 
In practice, this is only a simplified assessment of the building settlements and comparing them with the limits of the standards or other guidelines $([10,16])$. However, this approach often contributes to an underestimation of the construction effort, and hence to the occurrences of states of emergency in the form of scratches or cracks of specific building components [13] (Figure 3).

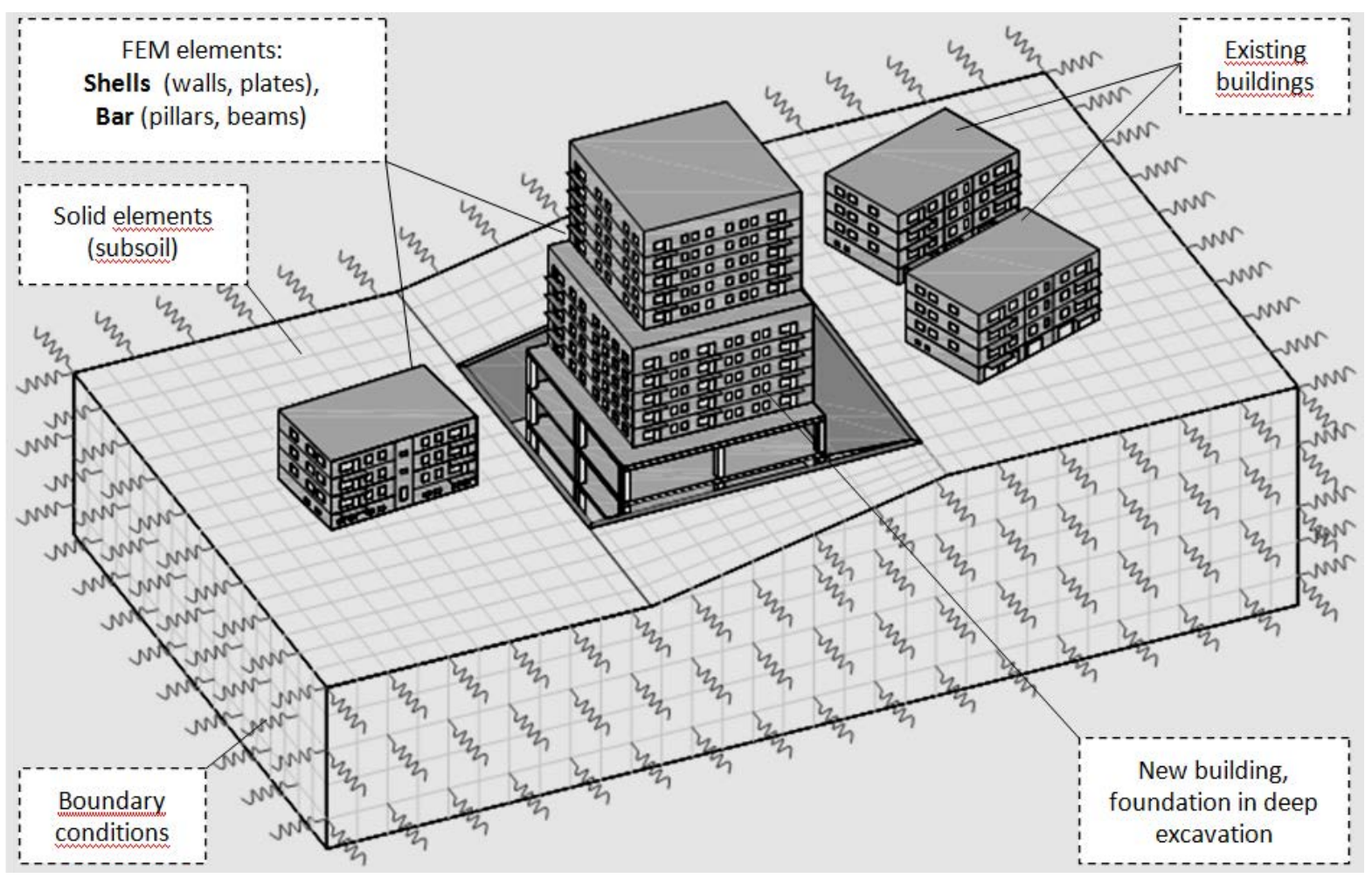

Figure 2. Spatial FEM model: new/deep foundation building -subsoil-neighbouring buildings
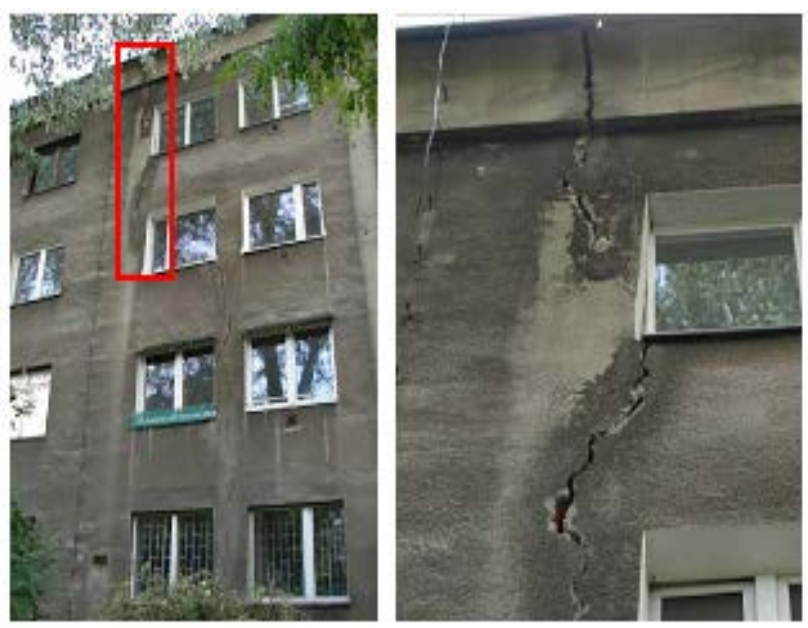

Figure 3. The outline of the building structure in the vicinity of a deep foundation of a new facility [13]

Thus, in principle, to reliably assess the condition of buildings in the zone of influence of the new facility, it would be necessary to determine, on the basis of the numerical analyses of the internal forces, the effort of individual construction components ([1,2,5,11,18]).

In order to simplify the numerical analyses (Figure 2) there has been developed the way to use the land subsidence curves behind the housing wall of the excavation, given in [12] and their implementation in the form of a plane of deformation to the FEM numerical model.

That methodology allows, among others, the analysis of the stress-strain state of the construction in a spatial arrangement, at any location in relation to the excavation housing as has been exemplified by calculation.

The analyses have been carried out in two phases, assuming that the analysed building, adjacent to the new facility in a deep foundation, is located at an angle of $15^{\circ}$ to the wall of the excavation housing:

- phase 1 - the determination of the stress and strain fields of construction prior to the excavation,

- phase 2 - the determination of internal forces arising from the new facility (the use of the generated plane of subsidence, developed on the basis of the curves, Michalak [12]).

\section{A Simplified Assessment of the Impact of the Deep Foundation on the Technical Condition of the Neighbouring Buildings}

A simplified method of assessment of the impact of deep foundation on the technical condition of the building in the neighbourhood consists in checking the condition in relation to the maximum displacement values of the structure $\left(\max \mathbf{s}_{\mathbf{k}}\right)[10]$ :

$$
\begin{aligned}
& \max _{k} \leq s_{k}^{u} \\
& \max s_{k} \leq s_{k}^{n^{*}}
\end{aligned}
$$

where $s_{k}{ }^{u} / s_{k}{ }^{n^{*}}$ - are the limit values of the structure displacement of the building in the ultimate and serviceability limit states [mm]. 


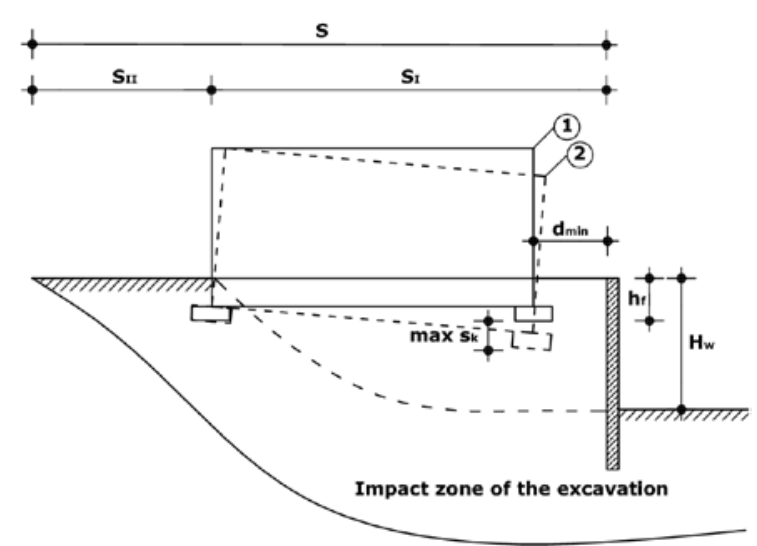

Figure 4. The maximum displacements of the structure (max sk): 1 state before the beginning of construction, 2 - state during construction, $\mathrm{S}$ - impact zone of the excavation (SI - coverage area of direct impact of the excavation, SII - coverage area of the secondary impact) [10]

The value of the maximum structure displacements (max sk) (Figure 4) is determined according to the following procedure:

- when the building is built at the depth of $h_{f}<2,5 m$ below the ground:

$$
\max s_{k}=v_{0}
$$

- when the building is built at the depth of $h_{f}>2,5 m$ below the ground:

$$
\max s_{k}=v_{0} \frac{H_{w}-h_{f}}{H_{w}}
$$

where $v_{0}$ - is the displacement of the area within the distance $d_{\min }$ of the housing [mm], $H_{w}$ - is the depth of the excavation $[\mathrm{m}]$.

Displacement values $v_{0}$, needed in equations (3) and (4) can be determined on the basis of:

- numerical analyses - mainly the Finite Element Method,

- analytical methods - analytical methods include the methods developed by Jen [8], Ilicheva [7], and Michalak [12].

\subsection{Determination of Displacements Based on the Finite Element Method}

As mentioned earlier, due to the equipment difficulties associated with the analysis of extensive numerical issues, the assessment of the risk to the buildings in the vicinity of the deep foundation of the new facility, with the use of FEM concerns:

- the determination of the vertical components of ground displacements at the site of the foundations of the existing building:

Whereas, such analyses are usually carried out in 2D flat system (Figure 5) $([3,4])$, rarely in the 3D system (Figure 6) ([20,21]), undoubtedly giving a broader perspective of what possibly could happen with the buildings adjacent to a deep excavation.

During numerical calculations the neighbouring buildings are entirely omitted or to a limited extent replaced by rigid blocks, designed to model the existing facilities (Figure 5).

- a comparison of the results obtained with the guidelines of standards (e.g. [10] - equations (1-2)).

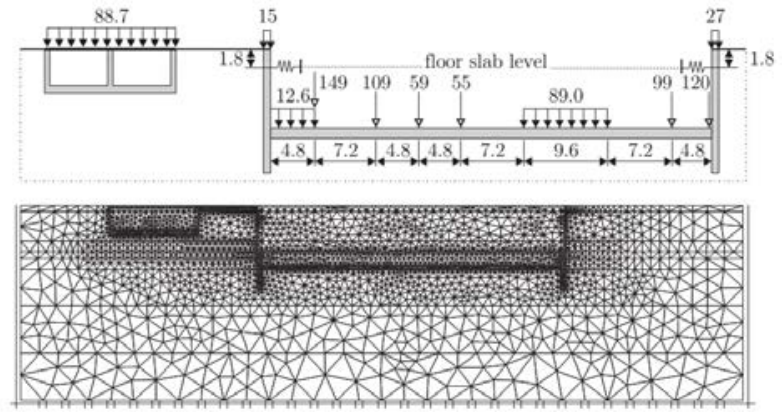

Figure 5. The FEM 2D model taking into account the substitute stiffness of the adjacent buildings [3]

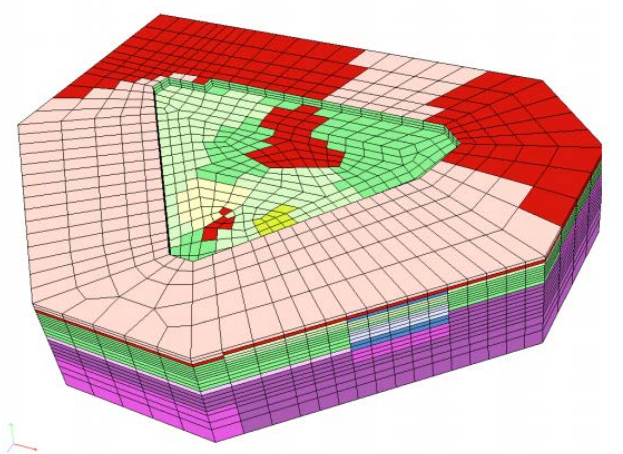

Figure 6. The 3D FEM model with the specified material zones [21]

\subsection{Determination of Displacements on the Basis of the Analytical Method}

Equations by Michalak [12] for describing the land deformation curve behind the housing wall of the excavation were developed by the author, as a function of its depth based on geodetic measurements and computer analyses.

The overall impact of the new construction of the building (the operation phase of construction - Figure 1b) may be assessed on the basis of the functions expressed by equations:

- when there are sandy soils under the foundation of the building:

$$
V(x)=\left(-0,00883 \frac{x^{2}}{h^{2}}+0,0482 \frac{x}{h}-0,0655\right) V_{0}
$$

- when there are coniferous soils under the foundation of the building:

$$
\begin{gathered}
V(x)=\left(-0,00614 \frac{x^{2}}{h^{2}}+0,0454 \frac{x}{h}-0,0652\right) V_{0} \\
V_{0}=\sum_{i=1}^{n} \frac{q^{*} \Delta \omega_{i} B\left(1-v_{i}^{2}\right)}{E_{0 i}}
\end{gathered}
$$

where $V_{0}$ - is the displacement of the ground surface directly behind the edge of the excavation housing $[\mathrm{m}], x$ - is the distance from the wall of the excavation [m], $h-$ is the depth of the excavation [m], $q^{*}-$ is the weight of the building $\left[\mathrm{kN} / \mathrm{m}^{2}\right]$, reduced by the value of the load from the underground part, $\omega$ - is a factor dependant on the shape and rigidity of the foundation, $B-$ is the width of the foundation of the newly erected building $[\mathrm{m}], E_{0}-$ is 
the initial loading modulus of soil [MPa], $v$ - is the Poisson's ratio of soil.

According to Michalak [12], the developed method can be used to estimate the impact of deep foundations on the neighbouring buildings in the case of excavations carried out by floor method or using diaphragm walls.

\section{Modelling of the Existing Buildings in the Vicinity of Deep Foundation - the Proposed Method}

In order to analyse the impact of deep foundation on the buildings in the vicinity, the methodology has been adopted that combines the analytical method with the Finite Element Method, by loading the existing building with kinematic excitation, on the basis of surface subsidence.

\subsection{Determination of Surface Subsidence of Land behind the Housing Wall of the Excavation}

The method by Michalak [12] has been chosen for the construction of the surface of the ground subsidence in the zone of impact of deep foundation because of the very wide range of applications.

The surface of the ground subsidence behind the housing wall of the excavation has been developed for the option - a building in the neighbourhood of "2" (Figure 9) using the equation (5), assuming that the newly built facility was erected by the floor method, and under its foundations there are sandy soils.

The data for the construction of the land displacement curve (Figure 7) are given in Table 1 and Figure 9.

Table 1. The summary of calculation data for the equation (5) describing the land deformation curie [18]

\begin{tabular}{|c|c|c|c|}
\hline \multicolumn{4}{|c|}{ The components of the equation (5), i - for layered subsoil } \\
\hline 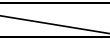 & $\mathrm{i}=1$ & $i=2$ & Units \\
\hline $\mathrm{h}$ & \multicolumn{2}{|c|}{9,00} & [m] \\
\hline $\mathrm{q}^{*}$ & \multicolumn{2}{|c|}{138,80} & {$[\mathrm{kN} / \mathrm{m} 2]$} \\
\hline$\Delta \omega$ & 0,40 & 0,82 & {$[-]$} \\
\hline $\mathrm{B}$ & \multicolumn{2}{|c|}{32,00} & [m] \\
\hline $\mathrm{V}$ & 0,30 & 0,25 & {$[-]$} \\
\hline E0 & 70000 & 80000 & {$[\mathrm{kN} / \mathrm{m} 2]$} \\
\hline V0i & 0,0231 & 0,0426 & [m] \\
\hline V0 & \multicolumn{2}{|c|}{0,0657} & [m] \\
\hline
\end{tabular}

On the basis of the equation (5), land subsidence curve has been developed (8) in a flat system (Figure 7), which was then approximated (stretched) to a three-dimensional system (Figure 8):

$$
V(x)=-7,18 \cdot 10^{-6} x^{2}+35,24 \cdot 10^{-5} x-43,10 \cdot 10^{-4}
$$

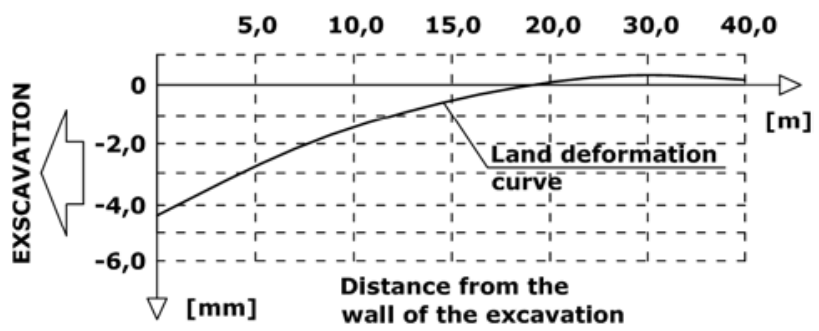

Figure 7. Land deformation curve behind the housing wall of the excavation obtained from the method by Michalak

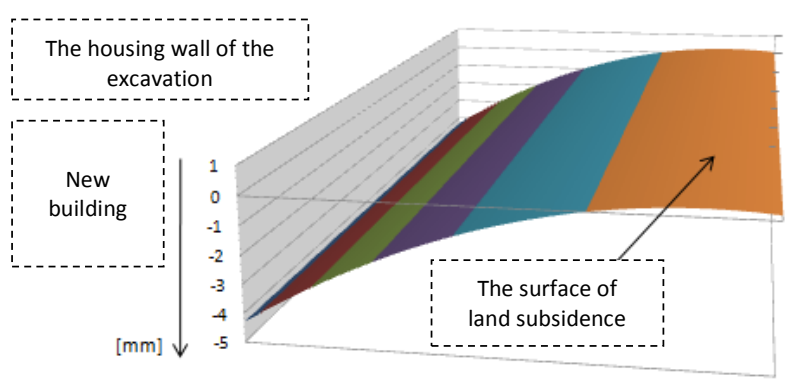

Figure 8. The surface of land subsidence behind the housing wall of the excavation

\subsection{Modelling of Specific Various Computational Stages}

Aby To generate the kinematic load, which is then implemented into the FEM numerical model, one must have the appropriate equation describing the deformation of the ground under the foundation of a model building in the vicinity of deep foundation, depending on its location in relation to the housing of the excavation.

The above methodology is illustrated by the following example of calculation:

- the building at an angle of $15^{\circ}$ (Figure 10b) to the housing wall of the excavation, was loaded with the kinematic load generated on the basis of a rotated subsidence surface, according to equation (10):

With this approach, the building located at an angle can be analysed as a non-rotated system, which greatly simplifies the modelling, and thus significantly reduces the time for the task.

The equation presenting land deformation has been obtained by rotating the subsidence surface (Figure 8) in relation to the " 0 " point by an angle $\alpha=15^{\circ}$ - in accordance with the location of the building in relation to the housing wall of the excavation (Figure 10b).

The coordinates of any "A" point in the system 0xy, after rotation of the land subsidence surface in relation to the " 0 " point can be represented by the equation:

$$
\left(\begin{array}{l}
x_{A}^{\prime} \\
y_{A}^{\prime}
\end{array}\right)=\left(\begin{array}{cc}
\cos \alpha & -\sin \alpha \\
\sin \alpha & \cos \alpha
\end{array}\right) \cdot\left(\begin{array}{l}
x_{A} \\
y_{A}
\end{array}\right)
$$

Thus, the modified equation (8) to the description of the land deformation at any point located at a distance from the housing wall of the excavation, after using a coordinate system as shown in Figure 10b, can be presented in the form of:

$$
\begin{aligned}
& V\left(\overline{X_{i}^{\prime}}\right)=-7,18 \cdot 10^{-6}\left(\overline{X_{i}^{\prime}}\right)^{2}+ \\
&+35,24 \cdot 10^{-5}\left(\overline{X_{i}^{\prime}}\right)-43,10 \cdot 10^{-4} \\
& \overline{X_{i}^{\prime}}=L+s-x_{i}^{\prime}=L+s-\left(x_{i} \cdot \cos \alpha-y_{i} \cdot \sin \alpha\right)
\end{aligned}
$$

where $\alpha$-is the rotation angle of the subsidence area of the "O" $\left.{ }^{\circ}\right], i$ - refers to any point located at a distance from the housing wall of the excavation, $\mathrm{L}-$ is the length of the modelled building [m], s - is the distance of the edge of the building from the housing wall of the excavation $[\mathrm{m}]$. 
Then, in a next calculation step on the basis of the equation (10), the generated kinematic excitations at the contact of the foundation with the subsoil, have been implemented to a computer program ORCAN [14] as a load of a FEM model building (Figure 11b).

\section{An Example of Calculation}

To illustrate the above procedure a calculation example was performed, assuming a building in the neighbourhood as constructed from reinforced concrete (Figure 10) - for the analysis the following variant has been selected - a building in the neighbourhood "2" (Figure 9), located close to the excavation made by the floor method (Figure 10b):
- wall thickness: $25 \mathrm{~cm}$, made of concrete B20 $\left(\mathrm{E}_{0}=29 \mathrm{GPa}\right.$ [15]),

- thickness of the slabs: $25 \mathrm{~cm}$, made of concrete B20 $\left(\mathrm{E}_{0}=29 \mathrm{GPa}\right.$ [15]),

- other geometric data are given in Figure 9.

For the discretisation of the computational area in ORCAN, square and triangular elements of the coating type were used. Calculations were performed in a spatial arrangement. The subsoil has been described using a contact model of the Winkler-type. Assuming the system of supporting layers of the ground as shown in Figure 9, the coefficient of the elastic subsoil was calculated which describes the ground under the foundation as $\mathrm{k}_{\mathrm{z}}=50782.50$ $\mathrm{kN} / \mathrm{m}$.

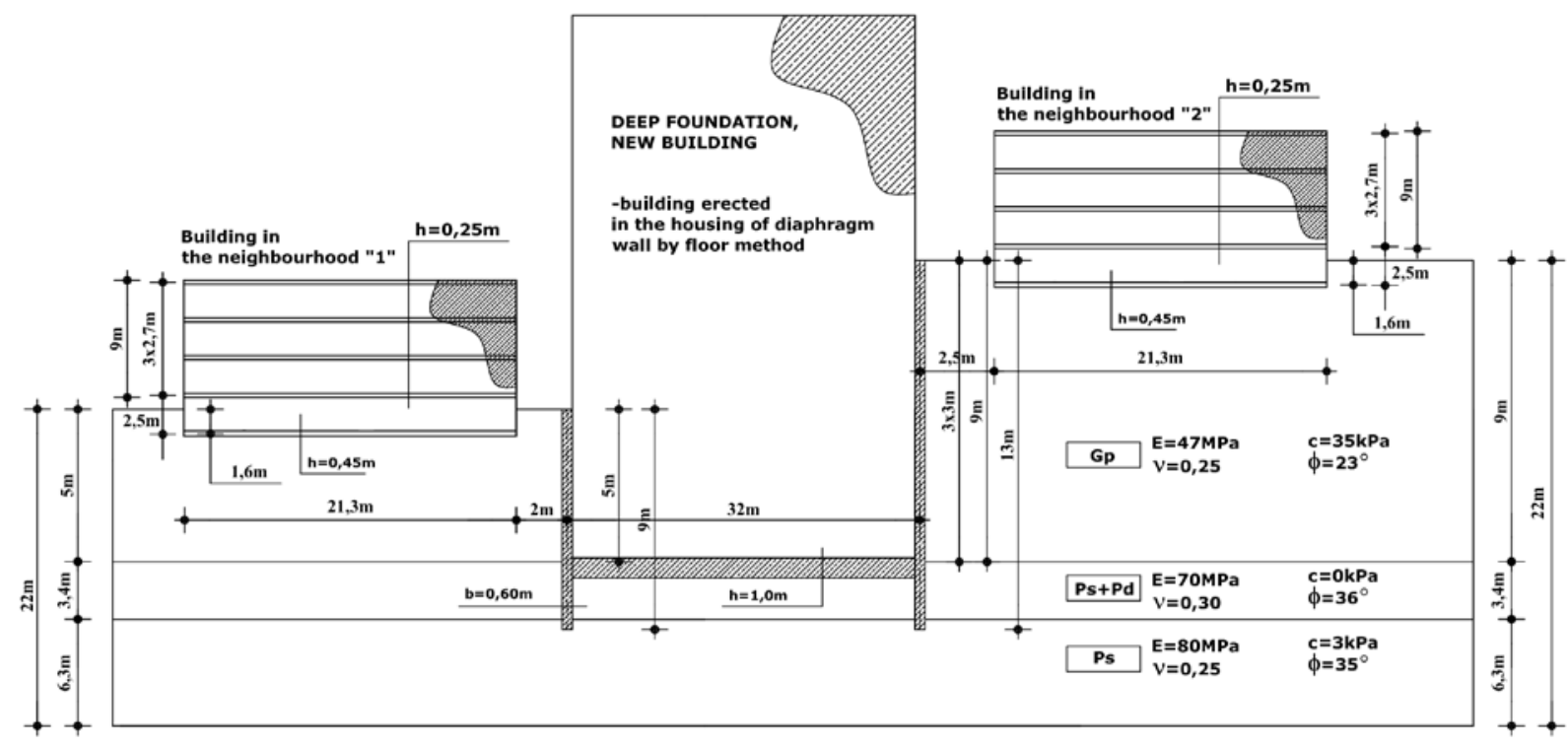

Figure 9. Diagram calculation of the analyzed system: dimensions of the structure, system load-bearing layers of the ground [23]
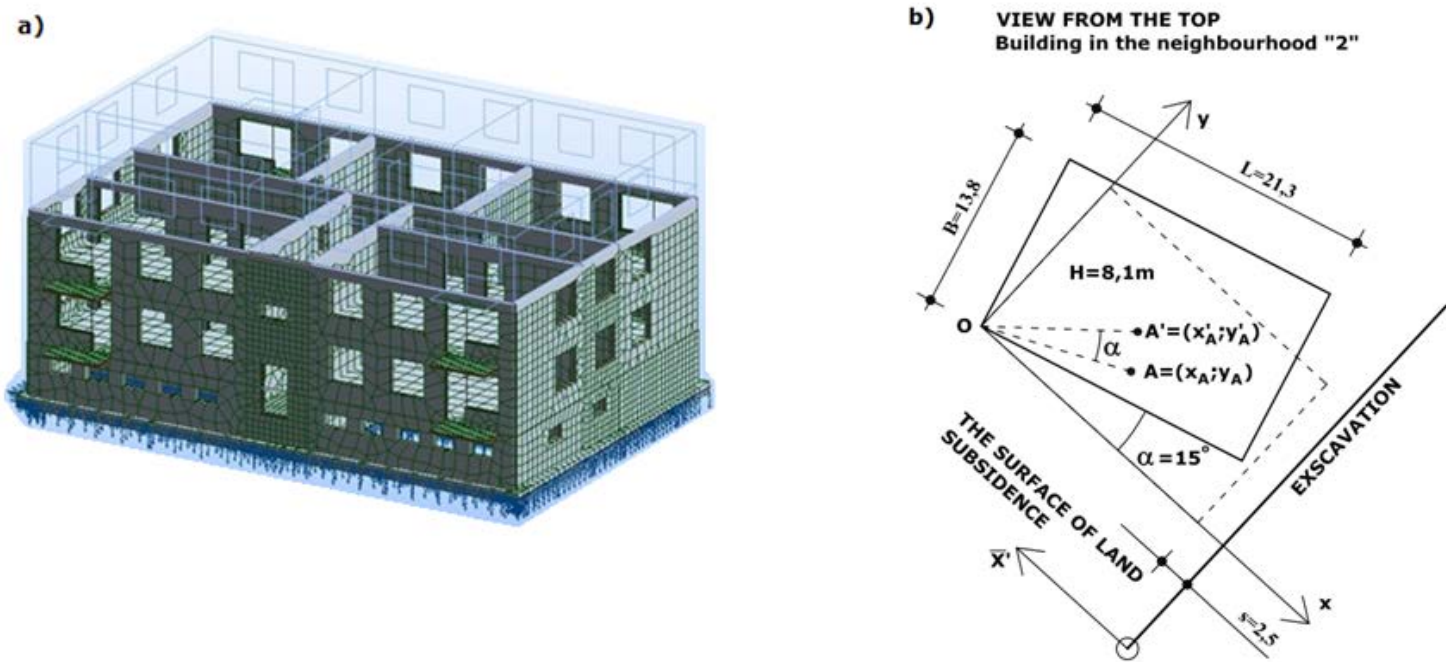

Figure 10. a) A static diagram of the analysed building with a sample discretisation, b) the location of the facility in relation to the housing wall of the excavation

In order to assess the impact of the excavation and the newly built facility on the adjacent buildings, numerical analyses were carried out in two phases of calculation:

- phase 1 (Figure 11a): the determination of the stressstrain state of the building in the neighbourhood before performing the excavation taking into account the usable load and the dead load of the wall and supporting ceilings,

- phase 2 (Figure 11b): the determination of the internal forces in the existing building resulting from the new facility (the load by kinetic excitation generated on the basis of a rotated subsidence surface - Figure 8). 
a)

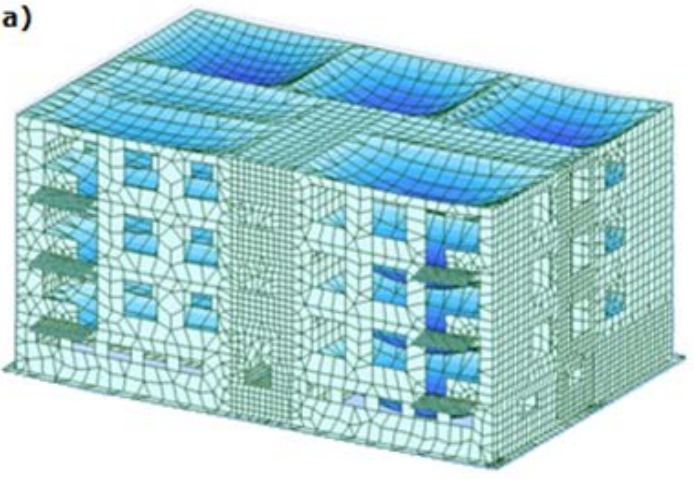

b)

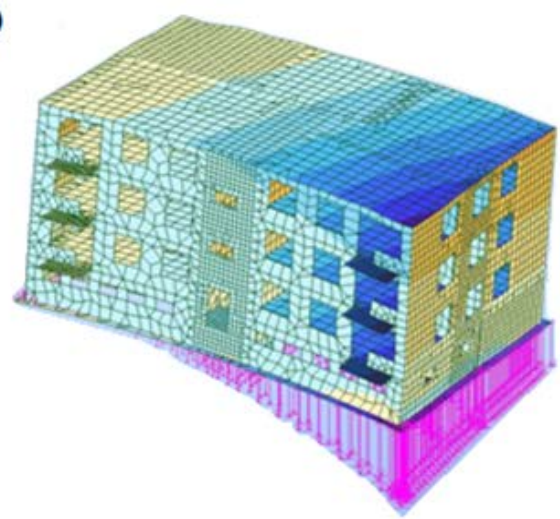

Figure 11. Computational phases / deformation of the building adjacent to the new facility: a) phase 1 - before constructing the facility, b) phase 2 -the building situated at an angle of $15^{\circ}$ to the housing wall of the excavation

In various computational phases, in order to enable the building a non-free glide over the ground [19], it was modelled on special supports (interfaces, enabling the foundation glide over the ground) with a coefficient of friction ratio between the foundation and the subsoil amounting to 0.55 [18].

\section{Results}

Sample results (phase 2 - the building loaded with the kinematic excitation, resulting from the new facility (Figure 11b)) are presented in the form of maps of:

- increases in the bending moments for dimensioning the "lower"/"upper" reinforcement along the "x" axis (Figure 12),

- increases in the bending moments for dimensioning the reinforcement in the walls of the basement / cellar (Figure 13).
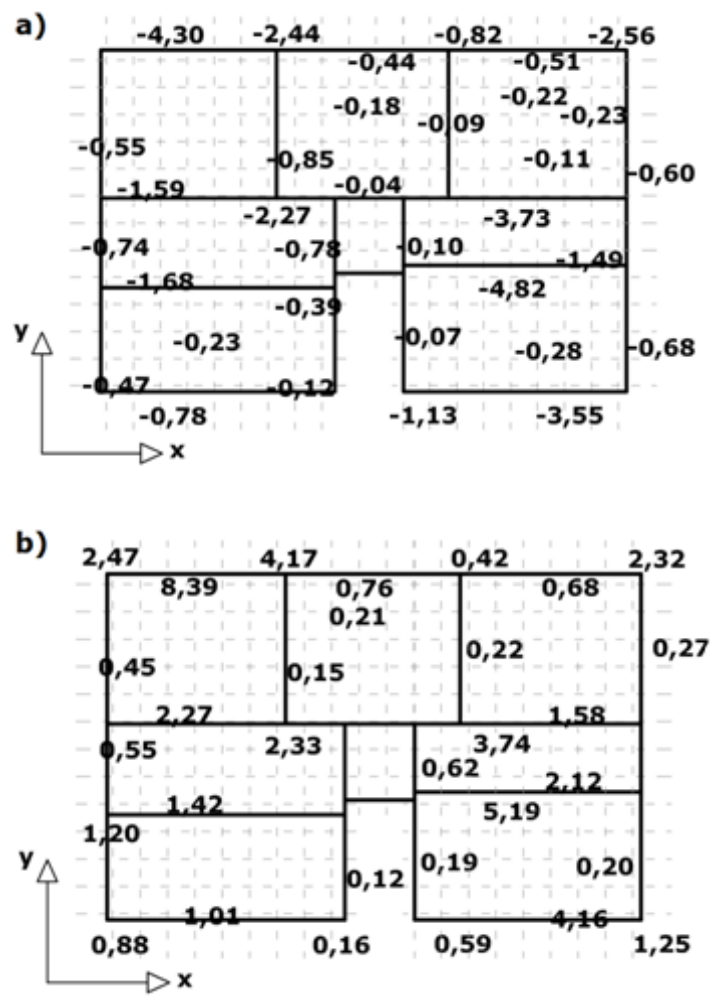

Figure 12. Substitute moments $\mathrm{Mx}^{*},[\mathrm{kNm} / \mathrm{m}]$ according to the method of Wood \& Armer to calculate the reinforcement in the cellar ceiling: a)"bottom", b) "top"

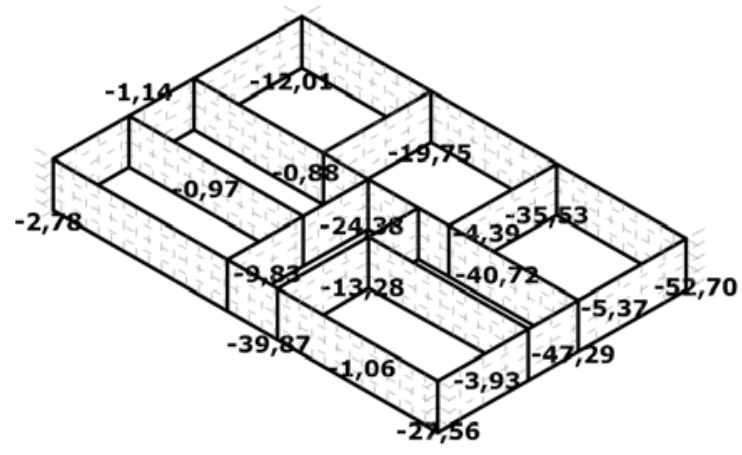

Figure 13. Substitute moments $[\mathrm{kNm} / \mathrm{m}]$ according to the method of Wood \& Armer to calculate the reinforcement in the walls of the basement/cellar

Whereas, due to the fairly significant values of increases of the torque moments (both in ceilings and walls of the analysed building), on Figure 12 and Figure 13 bending moments are presented in the substitute form (the correction of bending moments due to the torque) designated on the basis of the method by Wood \& Armer [22].

Substitute moments were calculated in cross sections of $0.5 \mathrm{~m}$ along the axis of the "x-x" and "y-y" of the adopted coordinate system (Figure 12, Figure 13).

Additionally, in Figure 14 there are diagrams of stresses for the longitudinal wall stiffening the analysed building.

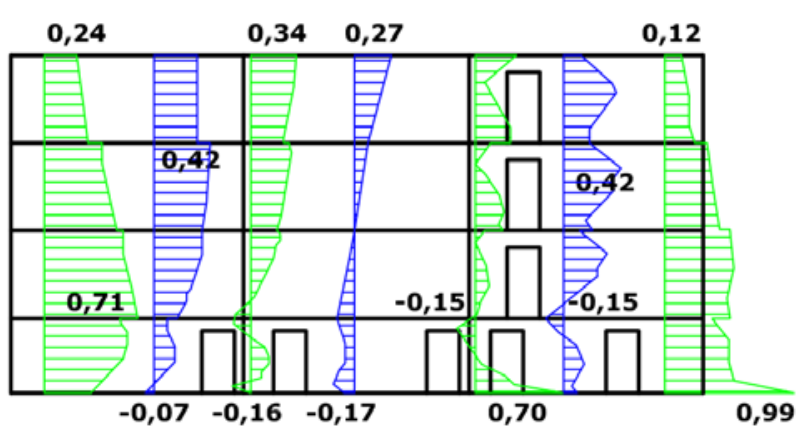

Figure 14. Principal stresses $\sigma_{11}[\mathrm{MPa}]$ in a longitudinal stiffening wall

\section{Conclusions}

The conducted calculations show that under the additional load, resulting from the construction of a new facility near the existing buildings, there appear additional 
internal forces in the analysed building, that have fairly large values. Particularly important are the stresses arising from torque due to the location of the building in relation to the excavation.

While analysing the given case, it is worth noting the principal stresses increase $\sigma_{11}$ in the wall stiffening the construction under calculation. The force distributions presented, indicate relatively tensile stress increase $(+)$ in the individual wall sections. This increase is as high as $50 \%$ of the average concrete tensile strength $\left(\mathrm{f}_{\mathrm{ctm}}{ }^{\mathrm{B} 20}=1.9\right.$ $\mathrm{MPa})$.

The results presented in the paper can be used in the next stage of the calculation (after taking into account the values obtained in phase 1 (Figure 11a)) to verify the ultimate limit states of loads and serviceability (e.g. scratches).

Therefore, when assessing the impact of deep foundation of the building on the technical condition of buildings in the neighbourhood, according to the presented effort method, the responsible person is fully aware of what is happening to the structure, and thus can make a fully justified decision as to its possible protection from damage.

\section{References}

[1] Bloodworth A.G.: Three-dimensional analysis of tunnelling effects on structures to develop design methods, PhD thesis, University of Oxford, 2002.

[2] Bloodworth A.G., Houlsby G.T., Burd H.J., Augarde C.E.: Threedimensional modelling of the interaction between buildings and tunnelling operations, Response of buildings to excavationinduced ground movements. Proceedings of the international conference held at Imperial College, London, UK, 2003, 189-199.

[3] Cudny M., Popielski P.: Analysis of excavation-induced deformation with different soil models, Task Quarterly 14, No 4, 339-362.

[4] Dinakar K. N., Prasad S. K.: Effect of deep excavation on adjacent buildings by diaphragm wall technique using PLAXIS, OSR Journal of Mechanical and Civil Engineering (IOSR-JMCE), 2632.

[5] Hou Y., Wang H., Wang J.: Numerical study of damage potential in buildings due to excavations, Journal of Shanghai Jiaotong University (Science), Vol. 15, No 2, 2010, 147-152.

[6] Horodecki G.A., Dembicki E.: Impact of deep excavation on nearby urban area, Proceedings of the 14th European Conference on Soil Mechanics and Geotechnical Engineering, Madrid/Spain, Millpress Science Publ., 575-580.
[7] Ilichev V. A., Nikiforova N. S., Koreneva E. B.: Method for calculating bed deformations of buildings near deep excavations, Soil Mechanics and Foundation Engineering, Vol. 43, No 6, 2006, 189-196.

[8] Jen L.C.: The design and performance of deep excavations in clay, $\mathrm{PhD}$ thesis, Massachusetts Institute of Technology, 1998.

[9] Korff M.,: Deformations and damage to buildings adjacent to deep excavations in soft soil, Deltares, 2009.

[10] Kotlicki W., Wysokiński L.: Security building in the vicinity of deep excavations, Building Research Institute, Warsaw, Poland, 2002 (in Polish).

[11] Liu G.: Numerical modelling of damage to masonry buildings dut to tunneling, $\mathrm{PhD}$ thesis, University of Oxford, 1997.

[12] Michalak H.: Deep foundations buildings and ground and building displacement in the neighborhood, Geoengineering-roads, bridges, tunnels, 04/2008, 66-76 (in Polish).

[13] Michalak A., Szulborski K., Woźniak M.: Security and monitoring of objects in the vicinity of deep excavations, XXIV National Labor Designer Design Workshops, Wisla, 2009, 229-264 (in Polish).

[14] ORCAN (Chyży. T.): Oriented Construction Analyser, (http://kmb.pb.edu.pl/dydaktyka/tchyzy/orcan.html).

[15] PN-EN 1992-1-1: 2008 Eurokod 2: Design of concrete structures (in Polish).

[16] Popa H.: Deep excavations in urban areas-influence on the neighbouring existing structures; numerical modelling and measurements, Scientific Journal-Series: Mathematical Modelling in Civil Engineering, No 1, 2010, 19-31.

[17] Siemińska-Lewandowska A.: Deep excavations. Design and construction, Publisher of Communications and Communications, Warsaw, 2010 (in Polish).

[18] Siwik D., Miedziałowski Cz.: Influence of deep building foundation on exsisting buildings Civil and Environmental Engineering, Vol. 4, No. 1, 2013, 61-68 (in Polish).

[19] Starosolski W.: Computer modeling of concrete engineering layouts, Publisher Silesian University of Technology, Gliwice, 2009 (in Polish).

[20] Thumann V.M.: Three dimensional ground deformation analysis of deep excavation adjacent to railway embankment in the city of Rotterdam, Plaxis Practice, 6-9.

[21] Truty A.: Computer modeling in geotechnical and construction issues, XXIV National Labor Workshop Designer, Wisla, 2009, 164-167 (in Polish).

[22] Wood R.H.: The reinforcement of slabs in accordance with a predetermined field of moments, Concrete, February 1968, August 1968 (correcpondence), 69-76.

[23] Zaczek-Peplińska J., Popielski P.: Utilisation of Geodetic Monitoring for Verificationof the Numerical Model of Impact of a Building under Construction on Surrounding Structures, FIG Working Week, Rome, 2012.

[24] Zienkiewicz O. C., Taylor R. L., Zhu J. Z.: The finite element method: its basis and fundamentals, Elsevier, ButterworthHeinemann, Amsterdam, 2005. 